\title{
Amorphous carbon nitride microband integrated in a microfluidic device for DNA biosensors applications
}

\author{
Marie-Charlotte Horny ${ }^{\mathrm{a}, \mathrm{b}}$, Florence Billon ${ }^{\mathrm{b}}$, Claude Deslouis ${ }^{\mathrm{b}}$, Mathieu lazerges ${ }^{\mathrm{d}}$, Vincent \\ Dupuis $^{\mathrm{c}}$, Jean-Michel Siaugue ${ }^{\mathrm{c}}$, Alain Pailleret ${ }^{\mathrm{b}}$ and Jean Gamby, \\ ${ }^{a}$ Centre de Nanosciences et de Nanotechnologies, C2N, CNRS, Université Paris-Saclay, UMR9001, 10 \\ Boulevard Thomas Gobert, 91120 Palaiseau, France. \\ ${ }^{b}$ Sorbonne Université, CNRS, Laboratoire Interfaces et Systèmes Electrochimiques (LISE, UMR 8235), 4 \\ place Jussieu, F-75005, Paris, France. \\ ${ }^{c}$ Sorbonne Université, CNRS, UMR 8234, Laboratoire PHysico-chimie des Electrolytes et Nanosystèmes \\ InterfaciauX (PHENIX), 4 place Jussieu, F-75005, Paris, France. \\ ${ }^{d}$ Université Paris Descartes, Faculté des Sciences Pharmaceutiques et Biologiques, 4 avenue de \\ l'observatoire, 75006 Paris, France.
}

* Corresponding author (CNRS, Université Paris-Saclay, Centre de Nanosciences et de Nanotechnologies): jean.gamby@.c2n.upsaclay.fr Tel: +33170270670 


\begin{abstract}
This study presents the use of new kind of carbon electrode materials as ultramicroelectrodes (UMEs) in the field of electrochemical DNA biosensors which has already been proven to be effective in protocols to DNA sequences hybridization. In contrast to other carbon materials such as diamond like carbon, that are difficult to integrate in microfluidic devices due to their high temperature deposition, amorphous carbon nitride $(\mathrm{a}-\mathrm{CNx})$ is easily synthesized at room temperature on various materials using sputtering techniques. Here, we report a-CNx use as microband electrodes in Glass/PDMS microfluidic devices. a-CNx electrodes were activated and then biofuntionalized by covalent grafting of a DNA probe as self-assembled monolayer (SAM) with a view to future development of a detection platform targeting circulating DNA or RNA sequences in microfluidic channels.
\end{abstract}

Keywords: nucleic acids; channel microelectrode; microfluidics; Amorphous Carbon Nitride; Impedance Spectroscopy. 


\section{Introduction}

Combining high specificity, low-cost, easiness to use, portability and compatibility with microfabrication processes, electrochemical DNA biosensors in microfluidics are excellent candidates for challenging methods using polymerase chain reaction (PCR) amplification in the frame of diagnosis of clinical interest. In this purpose, many recent works tackle to optimizing DNA biosensors in terms of cost, rapidity and limit of detection without an amplification stage. The choice of the immobilization technique depends on the biological element (DNA, RNA, miRNA), the transduction (electrochemical, optical, acoustic), the medium (serum, aqueous buffer), and the chemical stability of the probe [1]. Among a plethora of tested substrate materials, gold is widely used due to its facile deposition as thin film microelectrodes on various materials at room temperature, to its high conductivity and to numerous known functionalization methods such as physical adsorption, microcontact impression and polymerization. Physical adsorption is more attractive as it maintains the biological activity of the bioreceptors. Gold substrate provides an easy way to immobilize a DNA probe via the chemical adsorption, yielding to the formation of a self-assembled monolayer (SAM) using thiol-labelled probes [2-8].

However, SAMs on gold are known to be unstable architectures in time due to natural desorption of thiolated-DNA and gold dissolution in sodium chloride medium that impact negatively both the biosensor's robustness and sensitivity [9]. These drawbacks are especially critical for microfluidic devices due to the continuous convection flow [10],[11]. The need of stable biosensors in such microdevices is a key step for accurate real-time continuous monitoring of a wider range of bioanalytical applications. Among the many other alternative materials to gold, carbon-based surfaces for DNA sensing have also been of great interest [12]. In a non-exhaustive list, one can cite carbon paste [13], pencil lead [14], screen-printed carbon electrodes [15], carbon fiber [16], glassy carbon [17], or carbon materials resulting from pyrolysis of photoresists [18]. Additionally, carbon nitride based nanomaterials appears as promising new class for nanosensors. Among them, graphitic carbon nitride $\left(\mathrm{g}-\mathrm{C}_{3} \mathrm{~N}_{4}\right)$ and ultra-thin graphitic carbon nitride (utg$\left.\mathrm{C}_{3} \mathrm{~N}_{4}\right)$ and their hybridized forms: tubular form $\left(\mathrm{C}_{3} \mathrm{~N}_{4} \mathrm{NTs}\right)$, metallic (Au, Pt) nanoparticle-functionalized 
nanosheets (g- $\left.\mathrm{C}_{3} \mathrm{~N}_{4} @ \mathrm{Au} \mathrm{NPs}\right)$, or dots composite (g- $\left.\mathrm{C}_{3} \mathrm{~N}_{4} / \mathrm{NCDS}\right)$ can drastically enhance electrochemical performances in photocatalysis or sensing applications [19-23].

One of the covalent grafting strategies of DNA probe widely used in the literature is the one exploiting carbodiimide covalent binding. On the activated surface [17] of electrochemically oxidized glassy carbon electrodes, N-hydrosulfosuccinimide (NHS) and water soluble 1-ethyl-3-(3-dimethylaminopropyl)carbodiimide (EDC) reagents are known to activate carboxylic acid groups [24, 25], which favours strongly DNA grafting.

Despite their better performances than those of gold in terms of stability and selectivity, the main drawback of carbon materials, such as diamond like carbon (DLC) or boron-doped diamond (BDD), is their high deposition temperature which precludes to integrate them on other materials in MEMS or in microfluidic devices. In this work, we propose $a$-CNx thin film as an alternative carbon material deposited on transparent glass substrates using the DC cathodic reactive magnetron sputtering technique. The deposition involves a graphite target in the presence of an $\mathrm{Ar} / \mathrm{N}_{2}$ gas mixture. This technique presents a double advantage: first, the deposit can be easily produced at room temperature on a wide variety of polymeric or metallic substrates, and second, the possibility to tune the chemical surface composition [26] with a fine control of the atomic nitrogen content, $\mathrm{x}$, being typically lower than 0.4 [27].

The control of nitrogen composition leads to a high variety of dangling bonds. In addition, as for DLC and BDD, $a$-CNx materials offer a large potential window typically between $3 \mathrm{~V}$ and $4 \mathrm{~V}$ depending on the supporting electrolyte, on the $\mathrm{x}$ value and on the $\mathrm{pH}$. For example perchlorate offers a potential window close to $3.8 \mathrm{~V}$ as shown in the I-V curves of references [28] or [29] for aCHNx or a-CNx respectively with the same limits fo the cathodic or anodic waves. In reference [28] potential window is also shown for $\mathrm{KCl}$ : the cathodic wave starts at the same potential value as for perchlorate, the anodic wave starting $300 \mathrm{mV}$ earlier than for perchlorate due to the oxidation wave of chloride. Therefore, in conditions closer to biological ones, the potential windows remains close 
to $3.5 \mathrm{~V}$. When $\mathrm{x}$ is equal to 0.16 , high values of the electron transfer rate constant are measured for usual fast redox systems [30].

Recently, a study based on spectroscopic, microscopic and electrochemical characterizations of several ITO/a-CNx $(0.12<\mathrm{x}<0.30)$ disk electrodes led us to conclude why $a$ - $\mathrm{CN}_{0.30}$, behaves both as a dielectric material (low electronic conductivity) and as an ideally polarizable interface (high polarization resistance) [31],[32].

In this work, a- $\mathrm{CN}_{0.12}$ (lowest nitrogen content) thin films were synthesized and lithographied on $\mathrm{Ti} / \mathrm{Pt}$ substrates so as to produce planar $(30 \mu \mathrm{m}$ wide) microband electrodes. Then, an anodic electrochemical pre-treatment was performed to activate these microband electrodes. Finally, the formation of DNA probe based SAMs was achieved on pre-treated $a$ - $\mathrm{CN}_{0.12}$ microelectrodes opening the door to a future development of detection platform in the context of real time detection of circulating biomarkers such as circulating microRNAs in microfluidics.

\section{Experimental}

\subsection{Reagents and chemicals}

Sodium chloride (NormaPur), methylene blue (Alfa Aesar), potassium ferricyanide (III), and potassium ferrocyanide (II) (Sigma-Aldrich) were used in the experiments without further purification. The labelled DNA probe $(\mathrm{P})$ and complementary miRNA-target $(\mathrm{T})$ (Integrated DNA Technologies) sequences are shown in Table 1. The melting temperature ( $\mathrm{Tm}$ ) given by the supplier is $64^{\circ} \mathrm{C}$ and the molecular weight $(\mathrm{MW})$ is $6500 \mathrm{~g} \mathrm{~mol}^{-1}$. The DNA probe oligonucleotides were synthesized with a $5^{\prime}$ amino modification and the target sequence, miRNA-122, is a fragment of interest for the diagnosis of liver cells in case of injury (hepatitis, alcoholism, obesity). The electrolyte used for the Electrochemical Impedance Spectroscopy (EIS) and Cyclic Voltammetry $(\mathrm{CV})$ measurements was made of an equimolar $(3 \mathrm{mM})$ aqueous solution of $\left[\mathrm{Fe}(\mathrm{III})(\mathrm{CN})_{6}\right]^{3-}$ and $\left[\mathrm{Fe}(\mathrm{II})(\mathrm{CN})_{6}\right]^{4-}$ containing also $0.5 \mathrm{M} \mathrm{NaCl}$ and $10^{-8} \mathrm{M}$ Methylene Blue (MB) [11],[33]. The measured $\mathrm{pH}$ of the solution was 6.4. 


\section{2. $a-\mathrm{CNx}$ microelectrode fabrication}

$a$-CNx thin layers similar to those used in this work have been described in a previous paper [31]. Instead of an ITO sublayer, a titanium / platinum $(5 \mathrm{~nm} / 50 \mathrm{~nm})$ bilayer is deposited on glass so as to promote $a$-CNx adhesion and to provide an electrical contact on glass. Then, $a$-CNx is deposited using a mask (see mask in Figure 1) as well as a DC magnetron sputtering setup (MP300S Plassys, deposition time: 20 min, power: $200 \mathrm{~W}$, total pressure before injection of the gas mixture: $\mathrm{P}_{\text {tot( } \mathrm{i})}<2.10^{-}$

${ }^{7}$ Torr) including a graphite target and containing a gas mixture composed of argon and nitrogen (total pressure: $\mathrm{P}_{\text {tot }}=\mathrm{P}_{\mathrm{Ar}}+\mathrm{P}_{\mathrm{N} 2}=0.4 \mathrm{~Pa}$, pressures ratio : $100 \times \mathrm{P}_{\mathrm{N} 2} / \mathrm{P}_{\text {tot }}=3 \%$ ). A $220 \mathrm{~nm}$ thickness was measured with SEM for the resulting film as described in reference [31]. XPS data were used for determining the stoichiometric coefficient, $x$, of $a$-CNx thin films by considering the nitrogen atomic percentage in the film divided by the sum of nitrogen and carbon atomic percentages in the film, i.e. the $\mathrm{N} /(\mathrm{N}+\mathrm{C})$ percentage ratio. The measured nitrogen atomic content was 0.12 . Then, a classical PDMS fluidic circuit was microfabricated and pre-treated with nitrogen plasma to favor its adhesion onto the glass slide supporting the glass $/ \mathrm{Ti} / \mathrm{Pt} / a-\mathrm{CNx}$ microelectrodes. The main steps of this microfabrication process are summarized in Figure 1.

\subsection{Apparatus and Electrochemical measurements}

The Electrochemical study was performed with a 2-electrode setup: $30 \mu \mathrm{m}$ wide $a$-CNx microband working electrode and $2 \mathrm{~mm}$ wide Pt microband counter-electrode (see Figure 1C). The huge ratio of the $\mathrm{CE}$ area with respect to the WE one $(\sim 67)$ allowed to use the former one as reference electrode simultaneously. A potentiostat (Gamry 600+) was used in CV and EIS experiments. The scan rate for CV experiments was set to $10 \mathrm{mV} \cdot \mathrm{s}^{-1}$ between $-1 \mathrm{~V}$ and $1 \mathrm{~V}$ and the frequency range used for EIS measurements was varied from 1 $\mathrm{MHz}$ to $0.1 \mathrm{~Hz}$. The sinusoidal AC signal excitation between the two microelectrodes was set to $10 \mathrm{mV}$ peak to peak, since DC was fixed to $0 \mathrm{~V}$. The EIS experimental data were simulated using Simad software developed at LISE laboratory. 
The microfluidic setup was connected to a NEMESYS programmable syringe pump allowing a flow rate in the range from $0.01 \mu \mathrm{L} . \mathrm{s}^{-1}$ to $5 \mu \mathrm{L} . \mathrm{s}^{-1}$.

\section{Results and discussion}

\section{1. $a-\mathrm{CNx}$ microelectrodes pre-treatment}

Usually, as grown $a$ - $\mathrm{CN}_{\mathrm{x}}$ thin films prepared by using the magnetron sputtering technique show moderate electrochemical reactivity. Depending upon the intended goal, this latter can be changed by electrochemical pretreatments in either acidic or basic aqueous solutions, impacting either on wettability, or on the sign of the electronic affinity resulting from the nature of the dangling bonds thus formed. For example, a cathodic pre-treatment carried out in a $0.5 \mathrm{M} \mathrm{H}_{2} \mathrm{SO}_{4}$ aqueous solution [30] substantially improved their surface reactivity resulting in high values of the standard electron transfer rate constant $\left(\mathrm{k}_{0}=5 \times 10^{-2}-10^{-1} \mathrm{~cm} \cdot \mathrm{s}^{-1}\right.$ for $\left[\mathrm{Ru}\left(\mathrm{NH}_{3}\right)_{6}\right]^{3+/ 2+},\left[\mathrm{Fe}(\mathrm{CN})_{6}\right]^{3-/ 4-}$ and $\left.\left[\mathrm{IrCl}_{6}\right]^{2-/ 3-}\right)$. Conversely, an anodic pretreatment in $\mathrm{KOH}$ allowed a better peak separation for detection of ascorbic acid and dopamine because it shifted in opposite directions the oxidation peaks of these two components [34],[35].

Here, an anodic activation in a $0.1 \mathrm{M} \mathrm{KOH}$ aqueous solution was performed because it favours an increase of oxygenated dangling bonds at the surface, mostly as carboxyl groups [35],[36] which are expected to facilitate amino-modified DNA strands grafting onto a- $\mathrm{CN}_{0.12}$ substrate surface. The optimized microband electrode pre-treatment consists in filling the microfluidic device with a 0.1 M KOH solution under a $0.5 \mu \mathrm{L} . \mathrm{s}^{-1}$ flow rate and applying a $2.7 \times 10^{-5} \mathrm{~mA}$ constant current for the anodic activation.

The hydrodynamic voltammograms are carried out on the as-grown microelectrode (layout A, Figure 2) and after electrochemical pre-treatment (layout B, Figure 2) in an equimolar solution of $\left[\mathrm{Fe}(\mathrm{III})(\mathrm{CN})_{6}\right]^{3-} /\left[\mathrm{Fe}(\mathrm{II})(\mathrm{CN})_{6}\right]^{4-}(3 \mathrm{mM}$ each) containing $\mathrm{NaCl}(0.5 \mathrm{M})$. In both cases, the steadystate currents shown in Figure 2 are read as experimental current plateau values. The limiting current ratio between experimental current, $\mathrm{I}_{\mathrm{exp}}$, and theoretical current, $\mathrm{I}_{\text {th }}$, as a function of the $1 / 3$ power 
of the volumetric flow rate (layout C, Figure 2) for the channel electrode can be estimated by using the Levich theory, for which Compton has proposed the following practical expression (see Equation 1) $[37-39]$.

$$
I_{l i m}=0.925 n F C^{0} D^{2 / 3} x_{e}^{2 / 3} w\left(\frac{4 Q}{h^{2} d}\right)^{1 / 3}
$$

where $n$ is the number of electrons exchanged, $\mathrm{F}$, the faraday constant, $D$ and $C^{0}$, the diffusion coefficient and the bulk concentration of electroactive species, $w$ and $x_{\mathrm{e}}$, the width and the length of the WE, $d$ and $h$, the width and height of the channel and $Q$ the flow rate. $w$ is equal to $d$ (see Figure 1C).

The $\mathrm{I}_{\text {exp }} / \mathrm{I}_{\text {th }}$ current ratio plotted as a function of the $1 / 3$ power of the flow rate (layout $\mathrm{C}$, Figure 2) approaches a value of 1, indicating that it matches rather well the Levich prediction [11],[40].

However, the $a-\mathrm{CN}_{0.12}$ pre-treatment seems to influence the current kinetics shape as it appears on the displayed straightened slopes. A more quantitative analysis of steady-state voltammograms was carried out according to the procedure proposed by Mirkin et al. [41] that allows the extraction of the standard rate constant, $k^{0}$. This latter was found equal to $5.6 \times 10^{-4} \mathrm{~cm} \cdot \mathrm{s}^{-1}$ on as-grown a- $\mathrm{CN}_{0.12}$ electrodes and to $1.3 \times 10^{-3} \mathrm{~cm} \cdot \mathrm{s}^{-1}$ after activation, i.e. on pre-treated a- $\mathrm{CN}_{0.12}$ electrodes. This is consistent with previous observations related to activation of glassy carbon [42] and amorphous carbon nitride [43] electrodes.

\subsection{DNA probe immobilization and miRNA-122 target detection}

The single strand DNA-NH$H_{2}$ probe $(P)$ immobilization for detecting the miR-122 sequence in a microfluidic device was performed via the protocol illustrated in Figure 3A. First, carboxyl groups on the pre-treated a-CN $\mathrm{CN}_{0.12}$ surface were activated by introducing a $2.10^{-7} \mathrm{M}$ EDC and $2.10^{-7} \mathrm{M}$ NHS solution mixture (diluted in bi-distilled water) inside the chip for 20 minutes. Then, a $0.15 \mu \mathrm{M}$ DNA$\mathrm{NH}_{2}$ probe dissolved in a $0.5 \mathrm{M} \mathrm{NaCl}$ aqueous solution was circulated, then the flow was stopped 
for three hours. The flushing was carried out by using deionized water $\left(2 \mu \mathrm{L} . \mathrm{s}^{-1}\right)$ and the SAM stability test was checked in $0.5 \mathrm{M} \mathrm{NaCl},\left(0.5 \mu \mathrm{L} . \mathrm{s}^{-1}\right)$ for 30 minutes. Hybridization of miR-122 target in $0.5 \mathrm{M} \mathrm{NaCl}$ was performed during 30 minutes under the same flow conditions.

The EIS experiments displayed in Nyquist plot (Figure 3B) were performed in the same electrolyte conditions to check each protocol step from as-grown a- $\mathrm{CN}_{0.12}$ until target hybridization test (Figure 3A). All the experiments were performed in an equimolar ferri-ferrocyanide electrolytic solution around $0 \mathrm{~V}$, the equilibrium potential. An appropriate Randles circuit (Figure 3C) was used here to simulate the impedance spectrum for each step. The electrolyte resistance or ohmic resistance, $R_{\Omega}$ (only dependent on the electrolyte conductivity and on the channel microelectrode size) is the limit at high frequency of the real part $\left(Z_{\mathrm{RE}}\right)$ in the Nyquist plot, while the sum of $R_{\Omega}$, charge transfer resistance $R_{\mathrm{ct}}$ (semi-circle diameter) and the diffusion impedance, $Z_{\mathrm{D}}(\mathrm{f}->0)$, is the limit at low frequency. Therefore, instead of a traditional double layer capacitance $C_{\mathrm{dl}}$ in parallel with the $R_{\mathrm{ct}}$, a constant-phase element CPE ( $Q_{\mathrm{dl}}$ and $\alpha$ parameters) was preferred due to the surface heterogeneity and/or the presence of 2-D distribution $(\alpha<1)$ of current and potential on the working electrode [4446]. The analytical expression used for simulation that corresponds to the selected Randles circuit presented in Figure $3 \mathrm{C}$ is given by

$$
\mathrm{Z}(\mathrm{f})=\mathrm{R}_{\Omega}+\frac{\left(R_{c t}+Z_{D}(f)\right)}{1+(j 2 \pi f)^{\alpha} Q_{d l}\left(R_{c t}+Z_{D}(f)\right)}
$$

where the diffusion-convection impedance $Z_{D}$ was approximated by the expression for a finite diffusion layer thickness, $\delta_{\mathrm{x}}$,

$$
\mathrm{Z}_{D}(\mathrm{f})=\mathrm{Z}_{D}(0) \frac{\tanh \left(\sqrt{j 2 \pi f \tau_{D}}\right)}{\sqrt{j 2 \pi f \tau_{D}}}
$$

In this equation, $\tau_{\mathrm{D}}$ is the time constant for diffusion and it is given by 


$$
\tau_{D}=\frac{\delta_{x}^{2}}{D}
$$

Therefore, equation (1) is valid if the diffusion layer which develops from the leading edge until the leaving edge of the microelectrode remains very small, i.e. for $0<x<x_{\mathrm{e}}$. The local diffusion layer thickness is then defined as [47],[48]

$$
\delta_{x}=3^{2 / 3} \Gamma\left(\frac{4}{3}\right)\left[\frac{D x}{S}\right]
$$

where $\Gamma$ is the Gamma function.

This assumption could be justified in our case for $Q=5 \times 10^{-4} \mathrm{~cm}^{3} \cdot \mathrm{s}^{-1}$ corresponding to the imposed constant volumetric flow rate, and with $D=10^{-5} \mathrm{~cm}^{2} \cdot \mathrm{s}^{-1}, x_{\mathrm{e}}=30 \mu \mathrm{m}, h=40 \mu \mathrm{m}$ and $d=300 \mu \mathrm{m}$. With these values, $\delta_{\mathrm{xe}}$ is estimated to about $2 \mu \mathrm{m}$, that leads to $\tau_{\mathrm{D}}$ values in the expected order of magnitude, i.e. $a$ few milliseconds.

The parameter values used for simulation are listed in Table 2 . As expected, the $R_{\Omega}$ values are similar between each step. The double layer capacitance is also not sensitive to the protocol, its value being in the same order of magnitude as for glassy carbon electrode (i.e. $20 \mu \mathrm{F} . \mathrm{cm}^{-2}$ ) [42]. Before pretreatment, the $\mathrm{R}_{\mathrm{ct}}$ value is about $112.7 \Omega . \mathrm{cm}^{2}$, then it decreases to $78.1 \Omega . \mathrm{cm}^{2}$ after a-CN $\mathrm{N}_{0.12}$ surface pre-treatment. Therefore, a DNA modified with a $-\mathrm{NH}_{2}$ ending group was selected as DNA probe for the miR-122 target detection. These ones are covalently grafted to the $a-\mathrm{CN}_{0.12}$ carboxyl groups (Figure 3A) that were previously activated with the EDC/NHS procedure [24]. After the immobilization step, $R_{c t}$ increases again and reaches $100 \Omega . \mathrm{cm}^{2}$. This behaviour is related to the grafted DNA probes which are negatively charged, hindering therefore the diffusion of the $\left[\mathrm{Fe}(\mathrm{III})(\mathrm{CN})_{6}\right]^{3-}$ redox probe towards the microelectrode. The stability of the grafted SAM was also checked by flushing the channel with deionized water $\left(2 \mu \mathrm{L} . \mathrm{s}^{-1}\right)$ and then with a blank solution $(0.5$ $\mathrm{M} \mathrm{NaCl}$ at $0.5 \mu \mathrm{L} . \mathrm{s}^{-1}$ for 30 minutes). As shown in Figure 3B (enlarged area) the low difference observed on the raw data $\left(<0.9 \Omega . \mathrm{cm}^{-2}\right)$ after the DNA stability test underlines that no SAM deterioration had occurred (unchanged $R_{\mathrm{ct}}$ value) throughout these tests. This observation is 
consistent with a robust and covalent grafting conversely to SAM on gold where a probe desorption stage was often observed.

The target hybridization experiment follows the protocol described by Kelley S. O. et al. [5] with the use of methylene blue (MB) as a redox intercalant to enhance the response sensitivity. MB is a redox intercalator that enhances electron transfer across double-stranded DNA. As illustrated in Figure 3A, MB reduction step is reversible with a redox potential that is lower than those allowing $\left[\mathrm{Fe}(\mathrm{III})(\mathrm{CN})_{6}\right]^{3-}$ reduction. The electrons are conducted from the $a-\mathrm{CN}_{0.12}$ microelectrode to the intercalated MB thanks to a hopping process and are then accepted by the ferrocyanide ions dissolved in solution. The oxidized form of MB is regenerated for a further electrochemical reduction. As obtained with the experiment, the hybridization with target miR-122 decreases the $R_{\text {ct }}$ value (blue curve) down to $41.6 \Omega . \mathrm{cm}^{2}$, a value lower than the one measured in the presence of the DNA probe only (green curve, $100 \Omega . \mathrm{cm}^{2}$ ), underlining the success of hybridization.

\subsubsection{Density of DNA-NH molecules immobilized onto pre-treated $a$-CNx electrodes}

The influence of increasing concentrations of DNA probes from 10 to $10^{4} \mu$ g. $\mathrm{mL}^{-1}$ (i.e. from 1.54 $\mu \mathrm{M}$ to $1.54 \mathrm{mM}$ ) on the grafting density is shown in Figure 4A. The plot of the difference between $R_{\mathrm{ct}}$ (as grown $a-C N_{x}$-DNA probe) and $R_{\mathrm{ct}}$ (pre-treated $a-\mathrm{CN}_{\mathrm{x}}$ ) reaches a plateau that may indicate the saturation of the $\mathrm{COOH}$ groups available for grafting. As illustrated in Figure 3A, the active surface, i.e. uncovered surface by the DNA- $\mathrm{NH}_{2}$ probes (ligand) is accessible for electroactive redox couple. In this case, the fraction of $a$-CNx microelectrode surface grafted with ligands can be estimated as follows

$$
\theta=1-\frac{R_{c t}^{\text {pre-treated }}}{R_{c t}^{D N A \text { probe }}}
$$

The experimental evolution of the surface grafting is plotted in Figure 4A according to equation (6) and the experimental curve is modelled with the Hill-Langmuir equation [49],[50], as follows 


$$
\theta=\frac{1}{1+\left(K_{A} /\left[D N A-N H_{2}\right]\right)^{n}}
$$

where $K_{\mathrm{A}}$ represents DNA- $\mathrm{NH}_{2}$ concentration that produces a half-maximal response, and $n$ is the Hill coefficient related to the cooperativity degree between the first ligands and the following ones throughout the immobilization step: if $n<1$, cooperativity tends to decrease, if $n=1$, there is no cooperativity or independent, if $n>1$, cooperativity tends to increase.

The result of the fitting procedure using equation (7) is illustrated in Figure 4B. The obtained values of $K_{\mathrm{A}}$ and $n$ are $(100.25 \pm 9.65) \mu \mathrm{g} \cdot \mathrm{mL}^{-1}$ and $2.41 \pm 0.65$, respectively. This latter value confirms an excellent cooperativity between ligands during the immobilization procedure. The observed plateau $\left(\theta_{\max }=0.52 \pm 0.16\right)$ in the high concentration range $\left(10^{3}-10^{4} \mu \mathrm{g} \cdot \mathrm{mL}^{-1}\right)$ suggests that the maximum $\mathrm{COOH}$ sites (available for EDC/NHS activation procedure) on pre-treated $a-\mathrm{CN}_{0.12}$ is reached and represents only $52 \%$ of the active surface of the microelectrode.

The maximal area covered by the DNA probes was estimated to $A_{\max }=4.68 \times 10^{-5} \mathrm{~cm}^{2}$ by taking into account that the WE electrode surface $\left(S_{\mathrm{WE}}\right)$ is about $9 \times 10^{-5} \mathrm{~cm}^{2}$. The cross-section of a DNA molecule was currently modelled as a square of $5 \mathrm{~nm}$ per side [51] leading to an occupied surface area of $A_{\mathrm{DNA}-\mathrm{NH} 2}=2.5 \times 10^{-13} \mathrm{~cm}^{2}$ per DNA-NH2 molecule. The maximum number, $N_{\max }$, of DNA$\mathrm{NH}_{2}$ immobilized represents the ratio between $A_{\max }$ and $A_{\text {DNA-NH2 }}$ i.e. $1.87 \times 10^{8}$ molecules and the binding site density was deduced as the ratio between $N_{\max }$ and $S_{\mathrm{WE}}$ i.e. $2.08 \times 10^{12}$ molecules.cm ${ }^{-2}$. This latter value is lower than the maximum amount of DNA attached on a surface and it is close to the value obtained on other materials in the literature [4],[11],[51],[52].

\section{Conclusion}

Amorphous carbon nitride $(a-\mathrm{CNx})$ thin films were developed as working electrode materials for the elaboration of a DNA biosensor. They were proved to be an alternative to gold or other carbon 
and diamond materials like carbon (DLC) or BDD. To this end, $a-\mathrm{CN}_{0.12}$ thin films were synthesized and lithographied on $\mathrm{Ti} / \mathrm{Pt}$ substrates so as to produce planar $30 \mu \mathrm{m}$ width microband electrodes. Then, an electrochemical pre-treatment was performed inside a microfluidic device to activate these microband electrodes, leading to a drastic increase of the charge transfer kinetics. Finally, a biofunctionalization protocol (EDC/NHS) leading to the formation of a robust DNA probe SAM was achieved. In future works, our goal is to compare the performances (LOD, specificity and sensitivity) of the miR-122 target capture (synthetic DNA target mimicking the liver-specific micro-ribonucleic acid 122 (miRNA122) on two different materials: as-grown $a$ $\mathrm{CN}_{0.12}$, and pre-treated $a-\mathrm{CN}_{0.12}$ microelectrodes.

\section{Acknowledgements}

This research was supported by the LabEx MiChem part of French state funds managed by the ANR within the Investissements d'Avenir program under reference ANR-11IDEX-0004-02, and partly supported by the French RENATECH network. 


\section{Declaration of Competing Interest}

The authors declare that they have no known competing financial interests or personal relationships that could have appeared to influence the work reported in this paper.

\section{Credit author statement}

Marie-Charlotte Horny: Conceptualization, Methodology, Investigation, Formal analysis, Software, Visualization. Florence Billon: Conceptualization, Methodology, Investigation. Claude Deslouis: Conceptualization, Methodology, Formal analysis. Mathieu lazerges: Conceptualization, Methodology. Vincent Dupuis: Conceptualization, Methodology. JeanMichel Siaugue: Conceptualization, Methodology. Alain Pailleret: Conceptualization, Methodology, Investigation. Jean Gamby: Conceptualization, Methodology, Investigation, Formal analysis, Supervision, Visualization, Validation, Resource, Project administration, Writing- Original draft, Review and Editing. 


\section{References}

[1] V. Perumal, U. Hashim, Advances in biosensors: Principle, architecture and applications, Journal of Applied Biomedicine, 12 (2014) $1-15$.

[2] C.D. Bain, J. Evall, G.M. Whitesides, Formation of monolayers by the coadsorption of thiols on gold: variation in the head group, tail group, and solvent, Journal of the American Chemical Society, 111 (1989) 7155-7164

[3] C.E.D. Chidsey, D.N. Loiacono, Chemical functionality in self-assembled monolayers: structural and electrochemical properties, Langmuir, 6 (1990) 682-691.

[4] A.B. Steel, T.M. Herne, M.J. Tarlov, Electrochemical Quantitation of DNA Immobilized on Gold, Analytical Chemistry, 70 (1998) 4670-4677.

[5] S.O. Kelley, E.M. Boon, J.K. Barton, N.M. Jackson, M.G. Hill, Single-base mismatch detection based on charge transduction through DNA, Nucleic Acids Res., 27 (1999) 4830-4837.

[6] K.M. Koo, L.G. Carrascosa, M.J.A. Shiddiky, M. Trau, Poly(A) Extensions of miRNAs for Amplification-Free Electrochemical Detection on Screen-Printed Gold Electrodes, Analytical Chemistry, 88 (2016) 2000-2005.

[7] K.M. Koo, L.G. Carrascosa, M.J.A. Shiddiky, M. Trau, Amplification-Free Detection of Gene Fusions in Prostate Cancer Urinary Samples Using mRNA-Gold Affinity Interactions, Analytical Chemistry, 88 (2016) 6781-6788.

[8] M.N. Islam, M.K. Masud, M.H. Haque, M.S.A. Hossain, Y. Yamauchi, N.-T. Nguyen, M.J.A. Shiddiky, RNA Biomarkers: Diagnostic and Prognostic Potentials and Recent Developments of Electrochemical Biosensors, Small Methods, 1 (2017) 1700131.

[9] L.Y.S. Lee, R.B. Lennox, Electrochemical Desorption of n-Alkylthiol SAMs on Polycrystalline Gold: Studies Using A Ferrocenylalkylthiol Probe, Langmuir, 23 (2007) 292-296.

[10] S. Choi, J.J.M. Chae, Nanofluidics, A regenerative biosensing surface in microfluidics using electrochemical desorption of shortchain self-assembled monolayer, Microfluidics and Nanofluidics, 7 (2009) 819.

[11] M.C. Horny, M. Lazerges, J.M. Siaugue, A. Pallandre, D. Rose, F. Bedioui, C. Deslouis, A.M. Haghiri-Gosnet, J. Gamby, Electrochemical DNA biosensors based on long-range electron transfer: investigating the efficiency of a fluidic channel microelectrode compared to an ultramicroelectrode in a two-electrode setup, Lab Chip, 16 (2016) 4373-4381.

[12] F. Lucarelli, G. Marrazza, A.P.F. Turner, M. Mascini, Carbon and gold electrodes as electrochemical transducers for DNA hybridisation sensors, Biosensors and Bioelectronics, 19 (2004) 515-530.

[13] J. Wang, E. Palecek, P.E. Nielsen, G. Rivas, X. Cai, H. Shiraishi, N. Dontha, D. Luo, P.A.M. Farias, Peptide Nucleic Acid Probes for Sequence-Specific DNA Biosensors, Journal of the American Chemical Society, 118 (1996) 7667-7670.

[14] J. Wang, A.-N. Kawde, E. Sahlin, Renewable pencil electrodes for highly sensitive stripping potentiometric measurements of DNA and RNA, Analyst, 125 (2000) 5-7.

[15] G. Marrazza, G. Chiti, M. Mascini, M. Anichini, Detection of Human Apolipoprotein E Genotypes by DNA Electrochemical Biosensor Coupled with PCR, Clinical Chemistry, 46 (2000) 31.

[16] D.J. Caruana, A. Heller, Enzyme-Amplified Amperometric Detection of Hybridization and of a Single Base Pair Mutation in an 18Base Oligonucleotide on a 7- $\mu \mathrm{m}$-Diameter Microelectrode, Journal of the American Chemical Society, 121 (1999) 769-774.

[17] K.M. Millan, A.J. Spurmanis, S.R. Mikkelsen, Covalent immobilization of DNA onto glassy carbon electrodes, 4 (1992) 929-932.

[18] S. Ranganathan, R. McCreery, S.M. Maji, M. Madou, Photoresist-Derived Carbon for Microelectromechanical Systems and Electrochemical Applications, Journal of The Electrochemical Society, 147 (2000) 277.

[19] M.L. Yola, N. Atar, Development of molecular imprinted sensor including graphitic carbon nitride/N-doped carbon dots composite for novel recognition of epinephrine, Composites Part B: Engineering, 175 (2019) 107113.

[20] H. Medetalibeyoglu, M. Beytur, O. Akyıldırım, N. Atar, M.L. Yola, Validated electrochemical immunosensor for ultra-sensitive procalcitonin detection: Carbon electrode modified with gold nanoparticles functionalized sulfur doped MXene as sensor platform and carboxylated graphitic carbon nitride as signal amplification, Sensors and Actuators B: Chemical, 319 (2020) 128195.

[21] M.L. Yola, N. Atar, Amperometric galectin-3 immunosensor-based gold nanoparticle-functionalized graphitic carbon nitride nanosheets and core-shell Ti-MOF@COFs composites, Nanoscale, 12 (2020) 19824-19832.

[22] C. Pelin Böke, O. Karaman, H. Medetalibeyoglu, C. Karaman, N. Atar, M. Lütfi Yola, A new approach for electrochemical detection of organochlorine compound lindane: Development of molecular imprinting polymer with polyoxometalate/carbon nitride nanotubes composite and validation, Microchemical Journal, 157 (2020) 105012.

[23] M.L. Yola, Sensitive sandwich-type voltammetric immunosensor for breast cancer biomarker HER2 detection based on gold nanoparticles decorated Cu-MOF and Cu2ZnSnS4 NPs/Pt/g-C3N4 composite, Microchimica Acta, 188 (2021) 78.

[24] S. Sam, L. Touahir, J. Salvador Andresa, P. Allongue, J.N. Chazalviel, A.C. Gouget-Laemmel, C. Henry de Villeneuve, A. Moraillon, F. Ozanam, N. Gabouze, S. Djebbar, Semiquantitative Study of the EDC/NHS Activation of Acid Terminal Groups at Modified Porous Silicon Surfaces, Langmuir, 26 (2010) 809-814.

[25] K.M. Millan, S.R. Mikkelsen, Sequence-selective biosensor for DNA based on electroactive hybridization indicators, Analytical Chemistry, 65 (1993) 2317-2323.

[26] H. Cachet, C. Debiemme-Chouvy, C. Deslouis, A. Lagrini, V. Vivier, Correlation between electrochemical reactivity and surface chemistry of amorphous carbon nitride films, Surface and Interface Analysis, 38 (2006) 719-722.

[27] P. Tamiasso-Martinhon, H. Cachet, C. Debiemme-Chouvy, C. Deslouis, Thin films of amorphous nitrogenated carbon a-CNx: Electron transfer and surface reactivity, Electrochim. Acta, 53 (2008) 5752--5759.

[28] A. Lagrini, C. Deslouis, H. Cachet, M. Benlahsen, S. Charvet, Elaboration and electrochemical characterization of nitrogenated amorphous carbon films, Electrochemistry Communications, 6 (2004) 245-248.

[29] H. Cachet, C. Deslouis, M. Chouiki, B. Saidani, N.M.J. Conway, C. Godet, Electrochemistry of Nitrogen-Incorporated Hydrogenated Amorphous Carbon Films, Journal of The Electrochemical Society, 149 (2002) E233.

[30] A. Benchikh, C. Debiemme-Chouvy, H. Cachet, A. Pailleret, B. Saidani, L. Beaunier, M.H. Berger, C. Deslouis, Influence of electrochemical pre-treatment on highly reactive carbon nitride thin films deposited on stainless steel for electrochemical applications, Electrochimica Acta, 75 (2012) 131-138. 
[31] M. Faure, F. Billon, A.M. Haghiri-Gosnet, B. Tribollet, C. Deslouis, A. Pailleret, J. Gamby, Influence of the atomic nitrogen content in amorphous carbon nitride thin films on the modulation of their polarizable interfaces properties, Electrochimica Acta, 280 (2018) 238-247.

[32] M. Faure, F. Billon, I. Le Potier, A.M. Haghiri-Gosnet, B. Tribollet, A. Pailleret, C. Deslouis, J. Gamby, Improvement of electrochemical detection of transthyretin synthetic peptide and its amino acids on carbon electrodes: Glassy carbon versus amorphous carbon nitride a-CNx, Electrochimica Acta, 296 (2019) 251-258.

[33] A. Nassi, F.X. Guillon, A. Amar, B. Hainque, S. Amriche, D. Maugé, E. Markova, C. Tsé, P. Bigey, M. Lazerges, F. Bedioui, Electrochemical DNA-biosensors based on long-range electron transfer: optimization of the amperometric detection in the femtomolar range using two-electrode setup and ultramicroelectrode, Electrochimica Acta, 209 (2016) 269-277.

[34] M. Benlahsen, H. Cachet, S. Charvet, C. Debiemme-Chouvy, C. Deslouis, A. Lagrini, V. Vivier, Improvement and characterization of the electrochemical reactivity of amorphous carbon nitride electrodes, Electrochemistry Communications, 7 (2005) $496-499$.

[35] R.A. Medeiros, A. Benchick, R.C. Rocha-Filho, O. Fatibello-Filho, B. Saidani, C. Debiemme-Chouvy, C. Deslouis, Simultaneous detection of ascorbic acid and dopamine with electrochemically pretreated carbon nitride electrodes: Comparison with boron-doped diamond electrodes, Electrochem. Commun., 24 (2012) 61-64.

[36] R.A. Medeiros, R. Matos, A. Benchikh, B. Saidani, C. Debiemme-Chouvy, C. Deslouis, R.C. Rocha-Filho, O. Fatibello-Filho, Amorphous carbon nitride as an alternative electrode material in electroanalysis: Simultaneous determination of dopamine and ascorbic acid, Anal. Chim. Acta, 797 (2013) 30-39.

[37] V.G. Levich, Physicochemical Hydrodynamics, Prentice-Hall, 1962.

[38] R.G. Compton, A.C. Fisher, R.G. Wellington, P.J. Dobson, P.a. Leigh, Hydrodynamic voltammetry with microelectrodes: channel microband electrodes; theory and experiment, The Journal of Physical Chemistry, 97 (1993) 10410-10415.

[39] C. Amatore, N. Da Mota, C. Sella, L. Thouin, Theory and Experiments of Transport at Channel Microband Electrodes Under Laminar Flow. 3. Electrochemical Detection at Electrode Arrays under Steady State, Analytical Chemistry, 82 (2010) $2434-2440$.

[40] M. Faure, A. Pallandre, S. Chebil, I. Le Potier, M. Taverna, B. Tribollet, C. Deslouis, A.-M. Haghiri-Gosnet, J. Gamby, Improved electrochemical detection of a transthyretin synthetic peptide in the nanomolar range with a two-electrode system integrated in a glass/PDMS microchip, Lab Chip, 14 (2014) 2800-2805.

[41] M.V. Mirkin, A.J. Bard, Simple analysis of quasi-reversible steady-state voltammograms, Analytical Chemistry, 64 (1992) 22932302.

[42] I.-F. Hu, D.H. Karweik, T. Kuwana, Activation and deactivation of glassy carbon electrodes, Journal of Electroanalytical Chemistry and Interfacial Electrochemistry, 188 (1985) 59-72.

[43] P. Tamiasso-Martinhon, H. Cachet, C. Deslouis, V. Vivier, Amorphous carbon nitride a-CNx microelectrode: Fabrication and characterization, Electrochemistry Communications, 12 (2010) 1074-1076.

[44] B. Hirschorn, M.E. Orazem, B. Tribollet, V. Vivier, I. Frateur, M. Musiani, Constant-Phase-Element Behavior Caused by Resistivity Distributions in Films: II. Applications, Journal of The Electrochemical Society, 157 (2010) C458-C463.

[45] B. Hirschorn, M.E. Orazem, B. Tribollet, V. Vivier, I. Frateur, M. Musiani, Constant-Phase-Element Behavior Caused by Resistivity Distributions in Films: I. Theory, Journal of The Electrochemical Society, 157 (2010) C452-C457.

[46] M. Musiani, M.E. Orazem, N. Pébère, B. Tribollet, V. Vivier, Constant-Phase-Element Behavior Caused by Coupled Resistivity and Permittivity Distributions in Films, Journal of The Electrochemical Society, 158 (2011) C424-C428.

[47] M. Lévêque, A, Les lois de la transmission de chaleur par convection, Ann. Mines, 13 (1928) 283-287.

[48] S.C. Ling, Heat Transfer From a Small Isothermal Spanwise Strip on an Insulated Boundary, Journal of Heat Transfer, 85 (1963) 230-235.

[49] A.V. Hill, PROCEEDINGS OF THE PHYSIOLOGICAL SOCIETY: January 22, 1910, in, 1910, pp. i-vii.

[50] I. Langmuir, THE ADSORPTION OF GASES ON PLANE SURFACES OF GLASS, MICA AND PLATINUM, Journal of the American Chemical Society, 40 (1918) 1361-1403.

[51] B. Sun, P.E. Colavita, H. Kim, M. Lockett, M.S. Marcus, L.M. Smith, R.J. Hamers, Covalent Photochemical Functionalization of Amorphous Carbon Thin Films for Integrated Real-Time Biosensing, Langmuir, 22 (2006) 9598-9605.

[52] Z. Lin, T. Strother, W. Cai, X. Cao, L.M. Smith, R.J. Hamers, DNA Attachment and Hybridization at the Silicon (100) Surface, Langmuir, 18 (2002) 788-796. 


\section{Tables}

\section{Table1}

\begin{tabular}{l|l|l}
\hline Name & Sequence & \\
\hline \hline Probe (P) & 5'-AmM C6-CAA ACA CCA TTG TCA CAC TGC-3' & \\
\hline miRNA-Target (T) & 5'-GC AGT GTG ACA ATG GTG TTT G-3' & \\
\hline
\end{tabular}

Table 1: Amino-Modified DNA probe (P) and miRNA-target (T) sequences. 
Table 2

\begin{tabular}{|c|c|c|c|c|c|c|c|}
\hline & $R_{\mathrm{e}}$ & $R_{c t}$ & $Q_{d l}$ & $\alpha$ & $Z_{D}(0)$ & $\tau_{\mathrm{D}}$ & $\chi^{2}$ \\
\hline & $\Omega \mathrm{cm}^{2}$ & $\Omega \mathrm{cm}^{2}$ & $\Omega^{-1} \cdot \mathrm{cm}^{2} \cdot \mathrm{s}^{\alpha}$ & & $\Omega \mathrm{cm}^{2}$ & $\mathrm{~ms}$ & \\
\hline $\begin{array}{c}a-\mathrm{CNx} \\
\text { as-grown }\end{array}$ & 0.29 & 112.7 & $1.76 \times 10^{-5}$ & 0.94 & 5.88 & 28 & 0.93 \\
\hline $\begin{array}{l}a-\mathrm{CNx} \\
\text { treated }\end{array}$ & 0.29 & 78.1 & $3.07 \times 10^{-5}$ & 0.92 & 2.57 & 48 & 0.99 \\
\hline $\begin{array}{l}\text { Probe } \\
\text { layer }\end{array}$ & 0.30 & 100 & $2.87 \times 10^{-5}$ & 0.91 & 4 & 23 & 0.69 \\
\hline stability & 0.30 & 100 & $2.79 \times 10^{-5}$ & 0.92 & 4.82 & 48 & 0.68 \\
\hline Target & 0.30 & 41.6 & $3.38 \times 10^{-5}$ & 0.89 & 1.98 & 27 & 1.8 \\
\hline
\end{tabular}

$(*)$ Values of the resulting $\chi^{2}$ statistics were obtained with errors of fitted values, $\sigma=0.01$, for frequency ranging from $1 \mathrm{MHz}$ to $1 \mathrm{~Hz}$.

Table 2. Randles circuit parameters used for fitting in Figure 3 (see equations 2-3). 


\section{Figures}

\section{Figure 1}

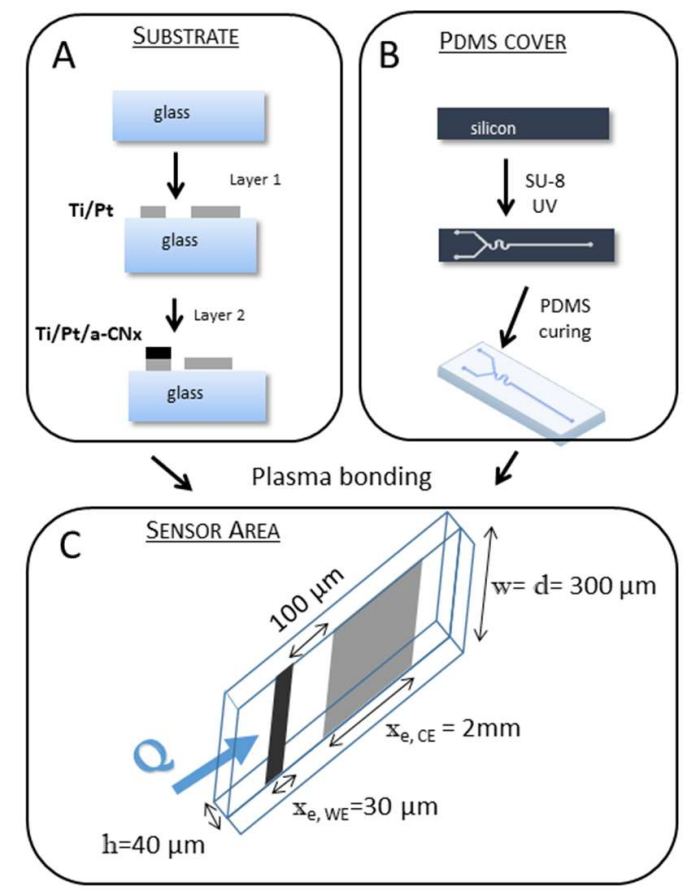

Fig. 1: Microfabrication key steps for a-CNx sensor microelectrode integration. A. Glass slides spin-coated with AZ5214 resin followed by an inverted lithography step and then metallized with a $200 \mathrm{~nm}$ thick a-CNx layer on the top of a $5 / 50 \mathrm{~nm}$ bilayer of titanium/platinum by two classical lift-off processes. B. Fluidic circuit master mold made with SU-8 on silicon wafer. PDMS layer is poured onto the SU-8 master mold to get a negative replica. The PDMS and the glass substrates with the electrodes are washed, dried and treated with nitrogen plasma for bonding. C. Detection area and fluidic channel microelectrodes with their dimensions. WE stands for $a$-CNx working electrode (width, $\mathrm{w}=300 \mu \mathrm{m}$, length, $\mathrm{x}_{\mathrm{e}}=30 \mu \mathrm{m}$ ), CE stands for platinum counter electrode $\left(\mathrm{w}=300 \mu \mathrm{m}, \mathrm{x}_{\mathrm{e}}=2 \mathrm{~mm}\right.$ ), and $\mathrm{h}$ and $\mathrm{d}$ represent the fluidic channel height and width, respectively. Note that here $\mathrm{w}=\mathrm{d}$. Q represents the flow rate and the arrow the flow direction. $\mathrm{CE}$ was purposely placed downstream of WE to avoid a parasitic additional current due to the species formed on the former one in the opposite configuration. 
Figure 2
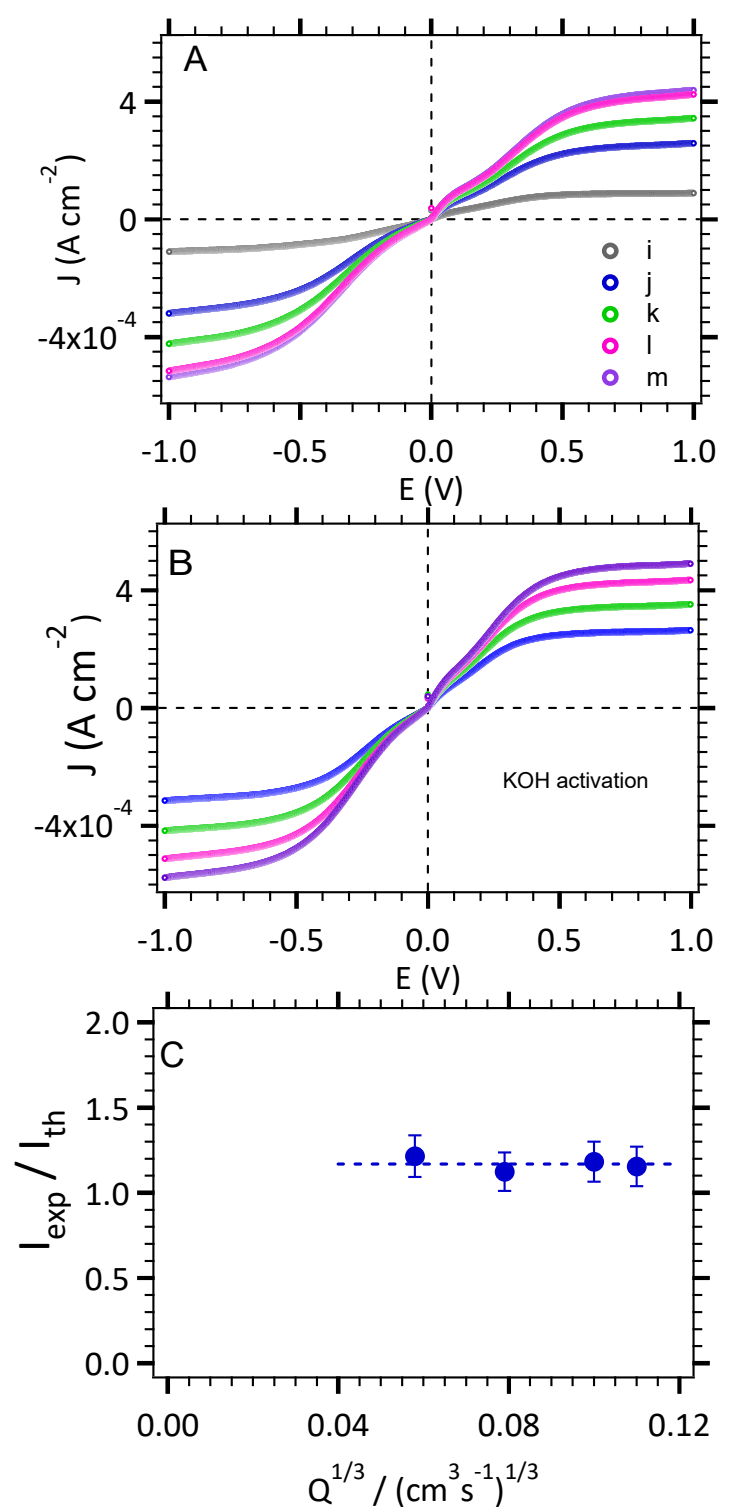

Fig. 2: $\mathrm{CV}$ experiments recorded in an aqueous solution containing $\mathrm{Fe}(\mathrm{CN})_{6}{ }^{4-} / \mathrm{Fe}(\mathrm{CN})_{6}{ }^{3-}(3 \mathrm{mM})$ and $\mathrm{NaCl}$ $(0.5 \mathrm{M})$ under various flow rates : static (i), $0.2(\mathrm{j}), 0.5(\mathrm{k}), 1.0(1), 1.5(\mathrm{~m}), \mu \mathrm{L} . \mathrm{s}^{-1}$. Scan rate : $10 \mathrm{mV} \cdot \mathrm{s}^{-1}$. A. at a as-grown $a-\mathrm{CN}_{0.12}$ microelectrode, B. at a pre-treated $a-\mathrm{CN}_{0.12}$ microelectrode. C. Plot of the limiting

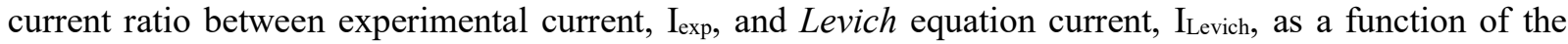
cubic root of the volumetric flow rate. The dotted line displays the mean ratio for experimental values to the theoretical ones. 
Figure 3

A

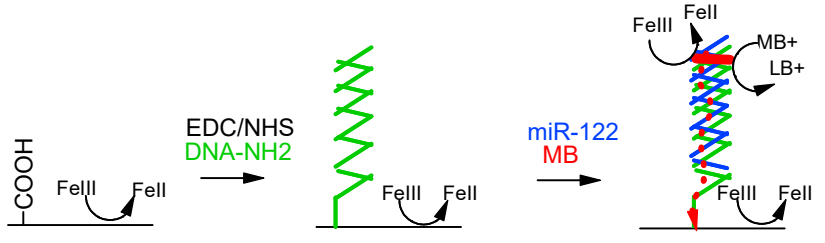

a. pre-treated b. DNA probe c. miR Target

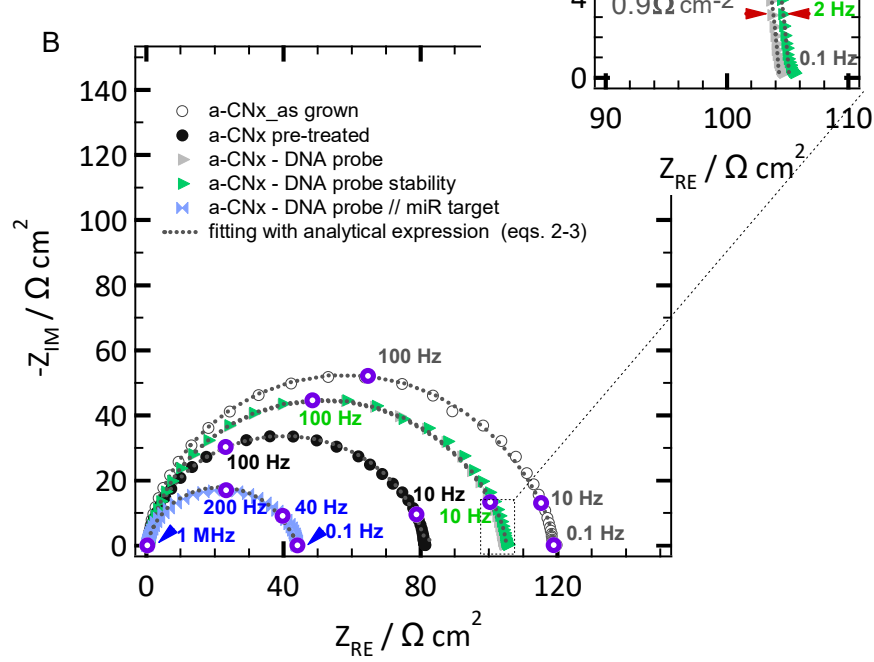

C

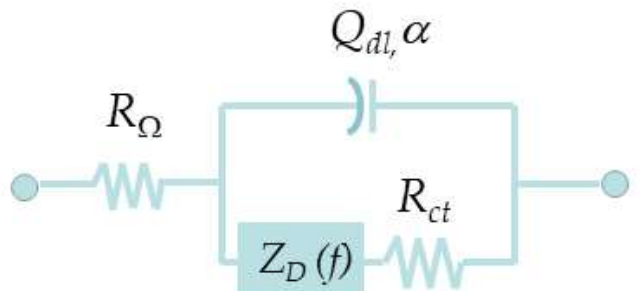

Fig.3: A. Hybridization protocol on a microchannel containing a a- $\mathrm{CN}_{0.12}$ electrode sensor for a working flow of $0.5 \mu \mathrm{L} \cdot \mathrm{s}^{-1}$ and in presence of $\left[\mathrm{Fe}(\mathrm{III})(\mathrm{CN})_{6}\right]^{3-} /\left[\mathrm{Fe}(\mathrm{II})(\mathrm{CN})_{6}\right]^{4-}(3 \mathrm{mM})+\mathrm{MB}\left(10^{-8} \mathrm{M}\right)$ in $0.5 \mathrm{M} \mathrm{NaCl}$ aqueous solution. B. EIS response of as grown $a-\mathrm{CN}_{0.12}(\mathrm{O})$, a- $\mathrm{CN}_{0.12}$ pre-treated $(\bullet)$ electrodes. Probe immobilized by circulating of $100 \mu \mathrm{g} \cdot \mathrm{mL}^{-1} \mathrm{DNA}$ probe sequence diluted in a $0.5 \mathrm{M} \mathrm{NaCl}$ aqueous solution 
$(\triangleright)$. Stability test of DNA probe layer after 30 minutes in a $0.5 \mathrm{M} \mathrm{NaCl}$ aqueous solution ( $)$.Target hybridization by introducing $10^{-18} \mathrm{M}$ of miR-122 $(\diamond)$. EIS curves simulated (dashed line) with analytical expressions given in equations 2 and 3. C. Equivalent circuit (Randles adapted) used to simulate the experimental impedance data.

\section{Figure 4}
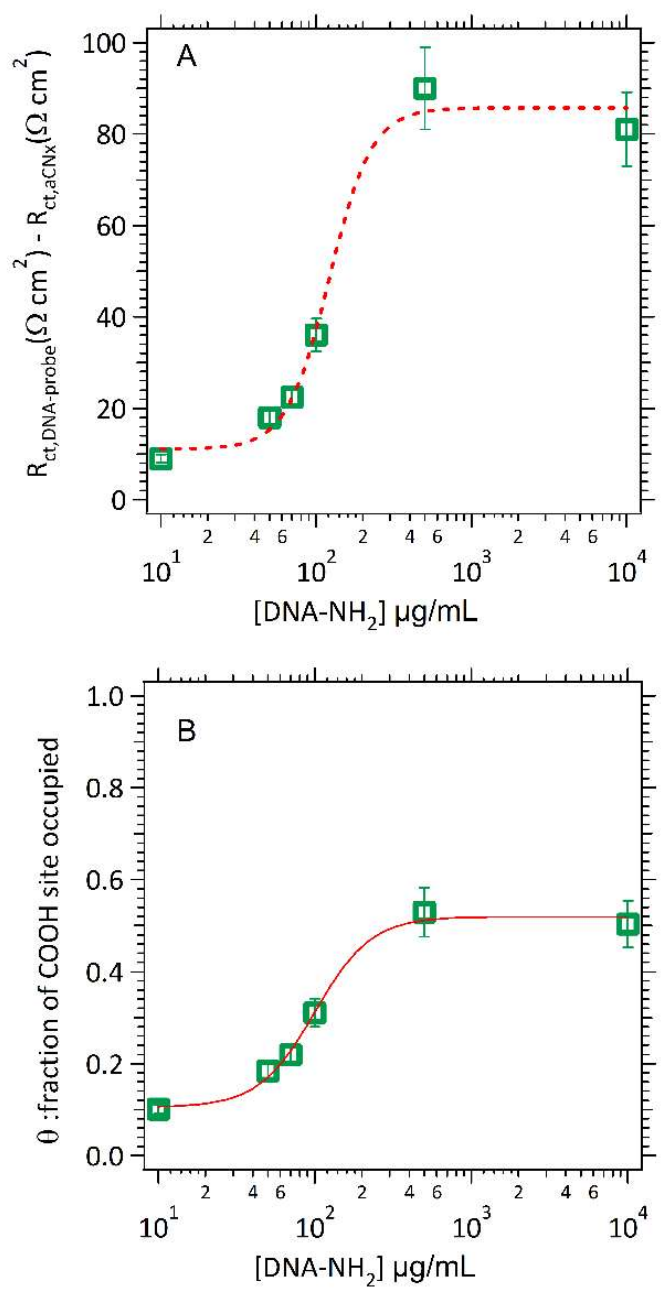

Fig.4: A. a-CN $\mathrm{CN}_{0.12}$ microelectrode functionalization response in EIS subjected to increasing concentrations of DNA probe. B. Experimental evolution of the surface grafting simulated with the Hill-Langmuir equation according to equation (7) where parameters $K_{\mathrm{A}}, n$, and $\theta_{\max }$ are equal to $(100.25 \pm 9.65) \mu \mathrm{g} \mathrm{mL}^{-1},(2.41 \pm$ $0.65)$, and $=(0.52 \pm 0.16)$, respectively. 
